\title{
A Pediatric Case of Solitary Myofibroma
}

Yukihiro Goto*, Hiroyasu Sasajima, Yuichi Furuno, Takuya Kawabe, Kei Ohwada, Kazunori Tatsuzawa, and Naoya Hashimoto

Department of Neurosurgery, Kyoto Prefectural University, Graduate School of Medicine, Kawaramachi-Hirokoji, Kamigyo-ku, Kyoto, 602-8566, Japan

*Corresponding author: Yukihiro Goto, Department of Neurosurgery, Kyoto Prefectural University, Graduate School of Medicine, Kawaramachi-Hirokoji, Kamigyo-ku, Kyoto, 602-8566, Japan, Tel: 81752515541; Fax: 81752515544; E-mail: y-go-to@koto.kpu-m.ac.jp

Received date: February 05, 2016; Accepted date: March 22, 2016; Published date: March 25, 2016

Copyright: $\odot 2016$ Goto Y, et al. This is an open-access article distributed under the terms of the Creative Commons Attribution License, which permits unrestricted use, distribution, and reproduction in any medium, provided the original author and source are credited.

\begin{abstract}
A 5-year-old male was referred to our department for evaluation of a firm elastic mass at the back of his head. Clinical examination revealed no abnormalities but the local area was tender. Further clinical and radiological examinations yielded no pathological findings and no other lesions were detected. The lesion was located in the diploic layer of the left parietal bone. The inner layer of the skull intact but the outer layer showed osteolytic change. The lesion did not adhere to the dura mater.

The tumor was completely removed with the surrounding bone. Histological examination revealed a mesenchymal tumor comprised of myoid spindle-shaped cells arranged in whorls between muscle cells and fibroblasts and a vascular component around the spindle cells. The final diagnosis was myofibroma. The patient recovered well after the operation and he was discharged from hospital 10 days after surgery. Clinical and radiological follow-up 6 and 12 months later showed neither recurrence of the primary lesion nor any indications of lesions at other sites.

Myofibroma is a benign neoplasm composed of myoid cells with thin-walled blood vessels. This tumor, reported to have a wide range of clinical manifestations, is one of the cranial vault tumors. These tumors occur mainly in children although a few affected infants have been reported. Surgical intervention may contribute significantly to the diagnosis of solitary myofibroma and complete removal achieves good outcomes. Herein, we report a 5-year-old male with solitary myofibroma of the skull, presenting as a firm elastic mass in the left parietal bone.
\end{abstract}

Keywords: Myofibroma; Skull; Pediatric

\section{Introduction}

Myofibroma is a benign neoplasm composed of myoid spindle cells arranged in whorls and vascular spaces with a hemangiopericytomalike appearance [1]. It presents in both solitary and multicentric forms. Although there are no histopathological differences between these two forms of myofibroma, differentiation in terms of biological behavior between the two has been described [2]. We experienced a 5-year-old child with a solitary myofibroma of the skull. Myofibroma of the skull is a rare entity and there are only a few case reports, mostly describing infants, in the literature [3-16]. Although this tumor shows clinical heterogeneity, complete surgical removal is usually diagnostic and can make a major contribution to achieving good outcomes for patients with solitary lesions. Herein, we report a myofibroma developing in the skull of a 5-year-old child.

\section{Case Presentation}

A 5-year-old male was referred to our hospital with a firm elastic mass, tender to palpation, at the back of his head on the left side. Cranial radiograms revealed an osteolytic oval lesion with a regular sclerotic rim, measuring $25 \mathrm{~mm}$ in maximum diameter, involving the posterior aspect of the parietal bone (Figure 1). Blood and neurological examination results were normal. Computed tomography (CT) showed a left parietal intraosseous lesion. The mass was located in the diploic layer with lysis of the outer layer of the parietal bone, though the inner layer and the dura just below the lesion were appeared to be intact. On magnetic resonance (MR) images, the lesion had regular rims, and was iso intense on T1-weighted images and slightly hyperintense on T2weighted images. Contrast enhancement was intense and homogeneous with a hollow center. No other lesions were detected. From the radiological findings, Langerhans cell histiocytosis, an epidermoid cyst, or a venous malformation was suspected.

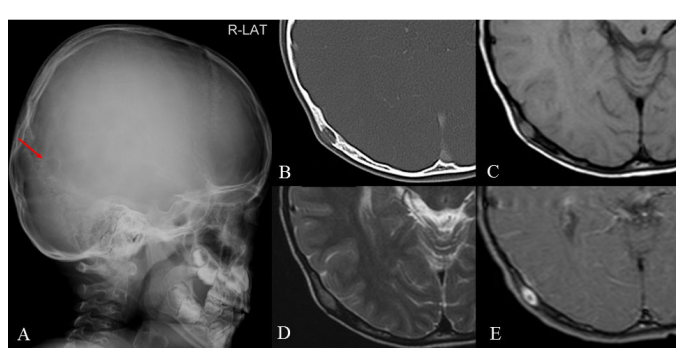

Figure 1: Posterior aspect of the parietal bone.

Surgical intervention was planned to remove the lesion. The lesion appeared under the periosteum as an erythematous elastic mass (Figure 2). We removed the tumor with the surrounding bone. The dura just below the lesion was intact. Histological examination revealed a lobular lesion composed of myoid spindle-shaped cells arranged in whorls between muscle and relatively loose collagen tissue, as well as a vascular component around the spindle cells, yielding a histopathological diagnosis of myofibroma of the skull. The patient recovered well and was discharged from our hospital 10 days 
Page 2 of 4

postoperatively. Clinical and radiological follow-up 6 and 12 months later showed neither recurrence of the primary lesion nor any indications of lesions at other sites.

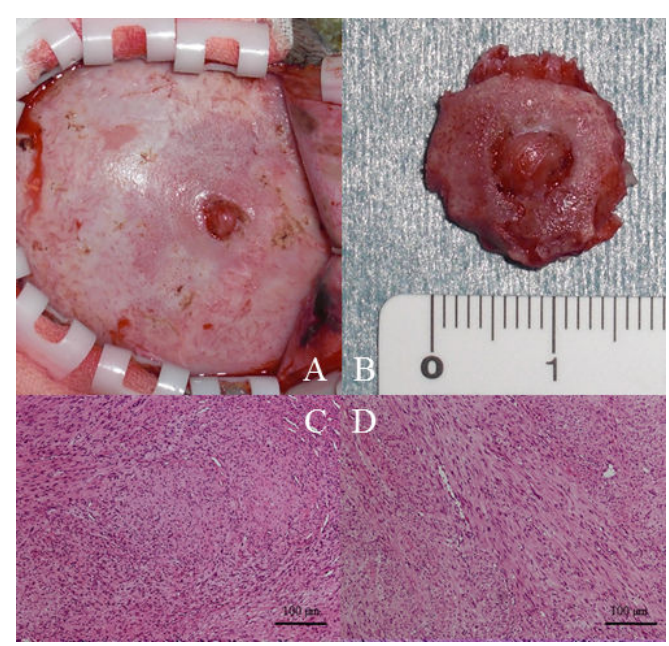

Figure 2: Lesion under the periosteum as an erythematous elastic mass.

\section{Discussion}

Infantile myofibromatosis, a mesenchymal disorder of early childhood, is characterized by the formation of myoid cells with thin- walled blood vessels in the skin, muscle, viscera, bone, and subcutaneous tissue [17].

This disorder was first classified as a unique entity by Stout in 1954 [18]. Since his report, various synonyms have been used to describe infantile myofibromatosis, but this entity is presently divided into two groups: solitary and multicentric forms, and, although rare, it is the most common fibrous tumor in infancy [2].

Myofibroma is the term used to describe a solitary lesion whereas multicentric lesions are referred to as myofibromatosis. While the multicentric form sometimes involves bone and viscera and the mortality rate approaches $70 \%$ with visceral involvement, solitary lesions usually have a benign clinical course [19]. The etiology of this tumor remains unclear; the clinical courses differ greatly though there are no histopathological differences between the solitary and multicentric forms. Bone is often involved in the multicentric form, while bone lesions are seen in a relatively small proportion of solitary form cases, only $10 \%$ [2]. Solitary lesions predominate in the head and neck soft tissues, followed by the upper extremities and trunk; the skull is a rare site for these lesions, with a review of the medical literature (using MEDLINE) yielding only 15 cases reported to date [3-16]. The clinical characteristics of these cases and our case are outlined in Table 1 .

\begin{tabular}{|c|c|c|c|c|c|c|c|c|}
\hline Author & Year & $\operatorname{Age}(\mathrm{m}) * / \operatorname{Sex}$ & Location & Size $(\mathrm{cm})$ & Symptom & $\begin{array}{l}\text { Plain } \\
\text { radiograph }\end{array}$ & Bone CT & $\begin{array}{l}\text { Surgical } \\
\text { outcome }\end{array}$ \\
\hline $\begin{array}{l}\text { Mizobuchet al. } \\
{[14]}\end{array}$ & 1986 & $12 / F$ & Parietal & 2.0 & Swelling & $\begin{array}{l}\text { Lytic } \\
\text { sclerosis }\end{array}$ & NA & NR \\
\hline Kuroiwa et al. [10] & 1990 & $6 / F$ & Parietal & 2.0 & Swelling & $\begin{array}{l}\text { Lytic } \\
\text { sclerosis }\end{array}$ & Hypodense mass & NA \\
\hline Inwards et al. [7] & 1991 & $8 / \mathrm{M}$ & Temporal & 3.5 & Swelling & NA & Hypodense mass & NR \\
\hline $\begin{array}{l}\text { Hasegawa et al. } \\
\text { [6] }\end{array}$ & 1993 & $7 / \mathrm{M}$ & Temporal & 2.2 & Swelling & $\begin{array}{l}\text { Lytic } \\
\text { sclerosis }\end{array}$ & Isodense mass & NR \\
\hline \multirow[t]{2}{*}{$\begin{array}{l}\text { Rutigliano et al. } \\
\text { [17] }\end{array}$} & 1994 & 7/F & Occipital & 4.0 & Swelling & Lytic lesion & Isodense mass & NR \\
\hline & 1994 & $45 / \mathrm{M}$ & Occipital & 8.0 & Swelling & Lytic lesion & Isodense mass & NR \\
\hline $\begin{array}{l}\text { Queralt } \\
\text { Poirier [16] }\end{array}$ & 1995 & $60 / M$ & Temporal & 1.5 & Swelling & Lytic lesion & NA & NA \\
\hline Detwiler et al. [3] & 1999 & $36 / \mathrm{M}$ & Parietal & 2.0 & Focal pain & $\begin{array}{l}\text { Lytic } \\
\text { sclerosis }\end{array}$ & Isodense mass & NR \\
\hline $\begin{array}{l}\text { Loundon et al. } \\
\text { [11] }\end{array}$ & 1999 & $48 / \mathrm{M}$ & Mastoid & NA & Otorrhea & NA & Hypodense mass & NR \\
\hline $\begin{array}{l}\text { Okamoto et al. } \\
{[15]}\end{array}$ & 2000 & $36 / \mathrm{M}$ & Temporoparietal & 4.3 & Swelling & $\begin{array}{l}\text { Lytic with } \\
\text { sclerosis }\end{array}$ & Highdense mass & NR \\
\hline Tsuji et al. [20] & 2004 & $48 / F$ & Frontal & 1.3 & Swelling & 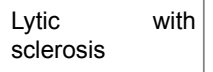 & Hypodense mass & NA \\
\hline Arva et al. [1] & 2008 & $8 / \mathrm{M}$ & Temporoparietal & 2.0 & Swelling & NA & Hypodense mass & NR \\
\hline
\end{tabular}


Page 3 of 4

\begin{tabular}{|c|c|c|c|c|c|c|c|c|}
\hline Galassi et al. [5] & 2008 & $17 / F$ & Skull base & NA & ** & NA & Isodense mass & NR \\
\hline Engel et al. [4] & 2011 & $84 / F$ & Frontal & 1.0 & Swelling & $\begin{array}{l}\text { Lytic with } \\
\text { sclerosis }\end{array}$ & Hypodense mass & NR \\
\hline $\begin{array}{l}\text { Merciadri et al. } \\
\text { [12] }\end{array}$ & 2011 & $108 / M$ & Frontal & 4.0 & Focal pain & $\begin{array}{l}\text { Lytic } \\
\text { sclerosis }\end{array}$ & Isodense mass & NR \\
\hline Our case & 2016 & $60 / \mathrm{M}$ & Parietal & 2.5 & Focal pain & Lytic lesion & Isodense mass & NR \\
\hline
\end{tabular}

Table 1: Clinical summary of 15 cases and our case.

Among the 15 reported cases, most patients were younger than 2 years of age, and the other were older children. Incidences did not differ between boys and girls. The lesion was usually round, measuring 1-4 $\mathrm{cm}$ except in one case with an $8 \mathrm{~cm}$ lesion, and temporal and parietal bones were common sites. Masses were generally elastic, firm and painless, with the presenting complaint being swelling of the scalp or feeling a lump. Only two cases were reported to have a tender mass, as in our case $[4,11]$. These tumors, depending on their location and surrounding structures, may cause focal symptoms; ptosis affecting the anterior skull base and otorrhea involving the mastoid bone have been reported $[3,6]$. The masses tend to expand from the diploic layer to both the inner and outer layers, however, there were no cases among the 15 reported in which tumor progression caused intracranial invasion. Few cases of true intraparenchymal myofibroma have been reported, raising the possibility that these lesions also originate in the walls of intra-axial vessels $[19,20]$.

Imaging findings of myofibroma are neither specific nor pathognomonic. The radiographic appearance is of well-defined osteolytic areas with or without a sclerotic rim [21]. As to MR imaging, lesions are usually hypointense on T1-weighted images, hyperintense on T2-weighted images, and homogeneously or heterogeneously enhanced with gadolinium [13]. The differential diagnosis usually includes Langherhans cell histiocytosis, epidermoid cyst, venous malformation (intraosseous hemangioma), osteomyelitis, and metastasis. Although less likely, osteoblastoma, fibrous dysplasia, interosseous meningioma, and fibrosarcoma are also included among the possible diagnoses.

There is a diversity of opinions regarding the surgical indications for myofibroma. In myofibromatosis as the multicentric form in neonates, spontaneous regression was reported [22]. Treatment is conservative if the lesion has already been definitively diagnosed histopathologically and there are no impending cosmetic or physical complications. On the other hand, in case the lesion presents a symptom such as tenderness, surgical intervention should be comprehensively considered rather than leave it untreated. In solitary myofibroma, surgical removal is preferred as this option assures diagnosis and management because solitary myofibroma reportedly has a favorable prognosis with a low recurrence rate of approximately $10 \%$ with total removal. Furthermore, as to skull tumors in the solitary form, past reports have shown no tumor recurrences in cases undergoing total removal.

\section{Conclusions}

When facing an osteolytic skull lesion with the aforementioned radiological features, myofibroma should be included in the differential diagnosis not only in neonates and infants but also in older children. Imaging findings of myofibroma are not pathognomonic. Though this tumor shows marked clinical heterogeneity, in solitary lesions, complete surgical removal for which the recurrence rate is about $10 \%$ and can usually be successfully treated with re-excision, usually confirms the diagnosis and contributes significantly to good outcomes.

\section{Author's Contributions}

Conception and design: Goto. Drafting the article: Goto. Treated the patient: Goto, Owada, Kawabe and Sasajima. Analyze the imaging data: Tatsuzawa. Critically revising the article: Hashimoto. All authors read and approved the final manuscript.

\section{Acknowledgment}

We thank Kei Yamada (Ph.D., Department of Radiology, Kyoto Prefectural University Graduate School of Medicine) for supply the MR images.

\section{Ethical Statement}

Identifying information of patient were all anonymized. This case report was written under the close rules of ethical committee of Kyoto Prefectural University Graduate School of Medicine.

\section{References}

1. Variend S, Bax NM, Van Gorp J (1995) Are infantile myofibromatosis, congenital fibrosarcoma and congenital haemangiopericytoma histogenetically related? Histopathology 26: 57-62.

2. Chung EB, Enzinger FM (1981) Infantile myofibromatosis. Cancer 48: 1807-18.

3. Arva NC, Nikas DC, Morris DE, Kovacs K, Wiley EL, et al. (2008) Solitary infantile myofibromatosis (myofibroma) of the skull: a case presentation and histopathological differential diagnosis. Pediatr Dev Pathol 11: 487-8.

4. Detwiler PW, Porter RW, Coons SW, Spetzler RF, Carrion CA, et al. (1999) Sporadic unifocal infantile myofibromatosis involving the skull. Case report. J Neurosurg 90: 1129-32.

5. Engel M, Thiele O, Mechtersheimer G, Hoffmann J, Freudlsperger C, et al. (2011) Solitary infantile myofibroma of the skull. J Craniofac Surg 22: e66-8.

6. Galassi E, Pasquini E, Frank G, Marucci G (2008) Combined endoscopyassisted cranionasal approach for resection of infantile myofibromatosis of the ethmoid and anterior skull base. Case report. J Neurosurg Pediatr 2: $58-62$. 
Citation: Goto Y, Sasajima H, Furuno Y, Kawabe T, Ohwada K, et al. (2016) A Pediatric Case of Solitary Myofibroma. J Neurol Disord 4: 263. doi: 10.4172/2329-6895.1000263

Page 4 of 4

7. Hasegawa T, Hirose T, Seki K, Hizawa K, Okada J, et al. (1993) Solitary infantile myofibromatosis of bone. An immunohistochemical and ultrastructural study. Am J Surg Pathol 17: 308-13.

8. Inwards CY, Unni KK, Beabout JW, Shives TC (1991) Solitary congenital fibromatosis (infantile myofibromatosis) of bone. Am J Surg Pathol 15: 935-41.

9. Kuroiwa T, Ohta T, Kazuki S, Ogawa R, Kobata H, et al. (1990) A Infantile myofibromatosis with a solitary lesion in the skull-case report. Neurol Med Chir 30: 184-7.

10. Loundon N, Dedieuleveult T, Ayache D, Roger G, Josset P, et al. (1999) Head and neck infantile myofibromatosis - a report of three cases. Int J Pediatr Otorhinolaryngol 51: 181-6.

11. Merciadri P, Pavanello M, Nozza P, Consales A, Ravegnani GM, et al. (2011) Solitary infantile myofibromatosis of the cranial vault: case report. Childs Nerv Syst 27: 643-7.

12. Mizobuchi K, Yoshino T, Ikehara I, Kawabata K, Tsutsumi A, et al. (1986) Infantile myofibromatosis: report of two cases. Acta Pathol Jpn 36: 1411-8.

13. Okamoto K, Ito J, Takahashi H, Emura I, Mori H, et al. (2000) Solitary myofibromatosis of the skull. Eur Radiol 10: 170-4.

14. Queralt JA, Poirier VC (1995) Solitary infantile myofibromatosis of the skull. AJNR Am J Neuroradiol 16: 476-8.
15. Rutigliano MJ, Pollack IF, Ahdab-Barmada M, Pang D, Albright AL (1994) Intracranial infantile myofibromatosis. J Neurosurg 81: 539-43.

16. Tsuji M, Inagaki T, Kasai H, Yamanouchi Y, Kawamoto K, et al. (2004) Solitary myofibromatosis of the skull: a case report and review of literature. Childs Nerv Syst 20: 366-9.

17. Wiswell TE, Davis J, Cunningham BE, Solenberger R, Thomas PJ, et al. (1988) Infantile myofibromatosis: the most common fibrous tumor of infancy. J Pediatr Surg 23: 315-8.

18. Stout AP (1954) Juvenile fibromatoses. Cancer 7: 953-78.

19. Spadola L, Anooshiravani M, Sayegh Y, Jequier S, Hanquinet S (2002) Generalised infantile myofibromatosis with intracranial involvement: imaging findings in a newborn. Pediatr Radiol 32: 872-4.

20. Kaplan SS, Ojemann JG, Grange DK, Fuller C, Park TS (2002) Intracranial infantile myofibromatosis with intraparenchymal involvement. Pediatr Neurosurg 36: 214-7.

21. Koujok K, Ruiz RE, Hernandez RJ (2005) Myofibromatosis: imaging characteristics. Pediatr Radiol 35: 374-80.

22. Miwa T, Oi S, Nonaka Y, Tamogami R, Sasaki H, et al. (2011) Rapid spontaneous regression of multicentric infantile myofibromatosis in the posterior fossa and lumbar vertebra. Childs Nerv Syst 27: 491-6. 